\title{
Epidemiological profile of women with endometriosis: a retrospective descriptive study
}

Jéssica Vilarinho Cardoso 1

iD https://orcid.org/0000-0002-6758-3664

Daniel Escorsim Machado 2

(iD) https://orcid.org/0000-0002-2640-8579

Mayara Calixto da Silva 3

https://orcid.org/0000-0002-6322-7865

Plínio Tostes Berardo 4

https://orcid.org/0000-0002-4426-699X

\author{
Renato Ferrari 5 \\ iD https://orcid.org/0000-0003-2684-7640 \\ Maurício Simões Abrão 6 \\ (iD) https://orcid.org/0000-0003-1320-3010 \\ Jamila Alessandra Perini 7 \\ https://orcid.org/0000-0002-7683-0698
}

\footnotetext{
1,3 Programa de Pós-guaduação em Saúde Pública e Meio Ambiente. Escola Nacional de Saúde Pública. Fundação Oswaldo Cruz. Rio de Janeiro, RJ, Brazil.

2,7 Laboratório de Pesquisa de Ciências Farmacêuticas. Fundação Centro Universitário Estadual da Zona Oeste. Av. Manuel Caldeira de Alvarenga, 1203. Rio de Janeiro, RJ, Brazil. CEP: 23.070-200. E-mail: jamilaperini@yahoo.com.br

4 Serviço de Ginecologia. Hospital Federal dos Servidores do Estado, Rio de Janeiro, RJ, Brazil;

5 Instituto de Ginecologia. Hospital Moncorvo Filho. Universidade Federal do Rio de Janeiro. Rio de Janeiro, RJ, Brazil.

6 Seção de Endometriose. Divisão de Ginecologia. Hospital das Clínicas. Faculdade de Medicina. Universidade de São Paulo. São Paulo, SP, Brazil.
}

\begin{abstract}
Objectives: to describe the epidemiological and clinical profile of women with endometriosis and to determine the association with the prognostic characteristics of the disease.

Methods: retrospective descriptive study involving 237 women attended at two referral hospitals for endometriosis, between 2011 and 2017. Associations between groups were estimated using logistic regression models.

Results: most women (65.4\%) were of reproductive age (29-39 years), with a body mass index in the range of 18.5-24.9 $\mathrm{kg} / \mathrm{m} 2$ and a high prevalence (23-81\%) of symptoms of the disease, with $49.5 \%$ being infertile. The average time of diagnosis was 5 years. Ovarian endometrioma and/or deep infiltrative endometriosis (DIE) were the most frequent type of endometriosis (87\%), and $59 \%$ of patients were in the III/IV stage of the disease. Approximately $87 \%$ of women with surgical diagnosis were aged over 30, married (70\%) and had lower parity. Dyspareunia was negatively associated with superficial endometriosis. Infertility was positively associated with age (30-39 years) and DIE in the uterine tubes; dysmenorrhea with DIE in the uterosacral ligament; cyclic intestinal complaints with DIE in the rectosigmoid and intestine, and with DIE classification and III/IV stage.

Conclusions: knowing the epidemiological and clinical profile of Brazilian women with endometriosis can help in diagnosis and treatment planning.
\end{abstract}

Key words Endometriosis, Epidemiology, Prognosis, Symptoms

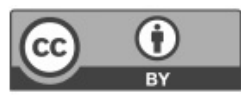




\section{Introduction}

Endometriosis is a gynecological disease defined by the presence of endometrial tissue outside the uterus, associated with different symptoms such as dysmenorrhea, chronic pelvic pain, dyspareunia, infertility and cyclical intestinal and urinary complaints. ${ }^{1}$ The disease's prevalence is not clearly established; however, it is estimated to affect approximately $10 \%$ of the premenopausal women, ${ }^{2}$ and $35-50 \%$ of infertile women. ${ }^{3,4}$ Endometriosis is a disease that entails a significant burden on women's quality of life and on healthcare systems, mainly due to the incapacitating symptoms of pain, the presence of infertility and the delay and high cost of diagnosis and treatment. 1,5,6 In addition, all health care costs involved with endometriosis were comparable to the other chronic conditions. 1

The etiology of endometriosis remains unknown, although the most accepted theory is regarding retrograde menstruation, described by Sampson, in 1927. However, many factors could be involved in the development and maintenance of ectopic implants, 1 such as hormonal, 7 inflammatory, ${ }^{8}$ genetic 4 and environmental ones.3Studies have shown that body mass index (BMI), 3,9 smoking 10 and physical activity 11 have an inverse association with endometriosis, although the mechanisms of these associations remain unclear. Other factors have also been associated with endometriosis, such as early age at menarche ${ }^{3}$ and infertility, 12 all conferring an increased risk, while parity 13 and oral contraceptive use ${ }^{3}$ are associated with a decreased risk. However, it is not known whether these associations are causes or consequences of endometriosis, and therefore should be interpreted with caution, mainly due to the inability to diagnose it before the onset of symptoms. ${ }^{1}$

Despite some studies have addressed the association between endometriosis and demographic factors, personal habits, menstrual and reproductive factors, the pathophysiology of the disease remains an enigma and the appropriate counseling of patients regarding prognosis is still challenging. 3,14,15 Thus, the aim of this study was to describe the epidemiological and clinical profile of women with endometriosis treated at two reference hospitals in Rio de Janeiro and to determine their relationship with prognostic values, diagnosis and symptoms of the disease.

\section{Methods}

This hospital-based retrospective descriptive study included 237 women recruited, between 2011 and 2017, from two reference hospitals in Rio de Janeiro. A convenience sampling was chosen to list the accessible population over a significant period for the clinical condition under study. All followed procedures were approved by the Brazilian Ethic Committees of the Hospital Federal dos Servidores do Estado (HFSE - 414/2011) and of the Hospital Moncorvo Filho da Universidade Federal do Rio de Janeiro (HMF/UFRJ -1.244.294/2015). The patients took part in a face-to-face interview, then provided written informed consent to allow their medical data to be collected, analyzed, and shared, and completed a demographic questionnaire during appointments.

Patients were eligible if they showed histologically confirmed endometriosis lesions or if they showed images of infiltrative endometrial lesions at magnetic resonance imaging (MRI). 16 Indications for performing surgery were: infertility without access to assisted reproduction techniques, pain refractory to clinical treatment, functional impairment of organs such as large bowel and/or urinary tract or bulky and/or suspected endometriomas. 17 According to the American Fertility Society Score, 4 patients with endometriosis diagnosed by surgery were divided in stages I/II and stages III/IV. Endometriotic lesions were classified into three groups: superficial endometriosis (SUP), ovarian endometrioma (OMA) or deeply infiltrating endometriosis (DIE), as described elsewhere. 3 Patients were excluded in the event of pregnancy or with only clinical suspicion of endometriosis or if surgical findings showed suspicion or evidence of malignancy or adenomyosis $(\mathrm{N}=32)$.

The following patients' characteristics were collected for this study: age, BMI, marital status, educational level, contraceptive use, personal habits (smoking, alcohol consumption, physical activity), family history of endometriosis, age at menarche, reproductive history (parity, infertility, spontaneous abortion), symptoms of endometriosis (dysmenorrhea, pelvic pain, dyspareunia, cyclical intestinal and urinary complaints), age at endometriosis diagnosis, diagnosis method, endometriosis staging and classification and ectopic loci affected by the disease.

BMI was categorized according to standard World Health Organization (WHO) cut-off points: underweight $\left(\mathrm{BMI}<18.5 \mathrm{~kg} / \mathrm{m}^{2}\right)$, normal weight $\left(18.5-24.9 \mathrm{~kg} / \mathrm{m}^{2}\right)$, overweight $\left(25-29.9 \mathrm{~kg} / \mathrm{m}^{2}\right)$, obese $\left(30-39.9 \mathrm{~kg} / \mathrm{m}^{2}\right)$ or morbidly obese $\left(\geq 40 \mathrm{~kg} / \mathrm{m}^{2}\right)$. In addition, the women were divided 
into two groups for statistical analysis: BMI $<25 \mathrm{~kg} / \mathrm{m}^{2}$ (underweight and normal weight), and BMI $\geq 25 \mathrm{~kg} / \mathrm{m}^{2}$ (overweight, obese and morbidly obese). The personal habits were self-reported, and we considered at least one year of practice/consumption. Only severe and incapacitating cyclic and acyclic pains were considered as symptoms of endometriosis. Infertility was defined as a couple not being able to conceive after 12 consecutive months of regular, contraceptive-free intercourse (primary or secondary). 4

A descriptive study was conducted, presenting relative frequencies for each categorical variable. Women were categorized according to prognostic values, diagnostic method, and presence of clinical symptoms, and evaluated for their association with the personal and clinical features.

Student's t-test was used to compare continuous variables between the studied groups, and results were expressed as mean \pm standard deviation (SD). Chi-square $\left(\chi^{2}\right)$ statistic test or Fisher's exact test, when applicable, were used to compare the differences between categorical variables. Multivariable logistic regression analyses were performed to identify possible confounding factors in the associations between variables and endometriosis features, which were estimated by the odds ratio (OR) with a $95 \%$ confidence interval (CI95\%). To elaborate the final regression model, we considered the biological significance of each variable and the degree of statistical significance in the univariate analysis ( $p$-value less or equal than 0.20). Differences were considered statistically significant when $p$-value was less than or equal to 0.05 . All analyses were performed using the Statistical Package for Social Sciences (SPSS Inc., Chicago, IL, USA), version 20.0.

\section{Results}

The sociodemographic characteristics of the 237 patients are summarized in Table 1. The mean age was $36.1 \pm 7.2$ years and more than half of women were married. Most participants had at least finished high school and had a mean BMI of $26.6 \pm 5.4$ $\mathrm{kg} / \mathrm{m} 2$. In addition, most of them practiced some regular physical activity, were never smokers and had some regular alcohol consumption. Regarding the reproductive history, most patients had at least one child and never had a spontaneous abortion. Besides, the majority of them use oral contraception and some had history of endometriosis in firstdegree relatives.
Regarding the age at menarche, it was observed the mean of $12.5 \pm 1.7$ years, with $43.5 \%$ of the patients reaching menarche between 12-13 years. The clinical characteristics of the study population are listed in Table 2. Laparoscopy was the most used diagnostic method and most patients diagnosed by surgery had stage III/IV endometriosis. The most patients presented at least three symptoms of gynecological pain (Figure 1) and almost half of women with endometriosis reported infertility (Table 2). Considering the number of painful symptoms, 32 women had only dysmenorrhea, 20 only deep dyspareunia and 3 only chronic pelvic pain; 40 women had dysmenorrhea and dyspareunia, 33 had dysmenorrhea and chronic pelvic pain and 2 had dyspareunia and chronic pelvic pain. Finally, 86 patients had dysmenorrhea, dyspareunia and chronic pelvic pain (Figure 1).

Fifteen $(6.3 \%)$ patients had only SUP endometriosis, $55(23.2 \%)$ only OMA and 56 $(23.6 \%)$ only DIE, 5 (2.1\%) women had SUP and OMA, 10 (4.2\%) had SUP and DIE and 72 (30.4\%) had OMA and DIE. In addition, 21 (8.9\%) patients with SUP and OMA were associated with DIE. Under these circumstances, most women had 2 to 4 affected loci with ovary being the most prevalent loci, followed by uterosacral ligament and by rectosigmoid (Table 2).

Figure 2 shows a comparison between asymptomatic and symptomatic women for dysmenorrhea (A), deep dyspareunia (B-D), cyclical intestinal complaints (E-H) and infertility (I-J), regarding the demographic, clinical and menstrual characteristics of the study population. Women with DIE in uterosacral ligament were more affected by dysmenorrhea $(\mathrm{OR}=2.8 ; \mathrm{CI} 95 \%=3.14-7.52)$. We also observed that patients with BMI higher than 25 $\mathrm{kg} / \mathrm{m}^{2}(\mathrm{OR}=1.97 ; \mathrm{CI} 95 \%=1.10-3.53)$, and who had any alcohol consumption $(\mathrm{OR}=2.13$; CI95\%= 1.20 - 3.82) were more affected by dyspareunia. However, woman with superficial endometriosis were less affected by dyspareunia $(\mathrm{OR}=0.25$; CI95\% $=0.11-0.57)$. The cyclical intestinal complaints were positively associated with DIE in the rectosigmoid $(\mathrm{OR}=3.78 ; \mathrm{CI} 95 \%=1.95-7.33)$ and intestine loci $(\mathrm{OR}=2.96$; $\mathrm{CI} 95 \%=1.31-6.65)$, and with DIE classification $(\mathrm{OR}=2.58$; CI95\% $=1.08-6.11)$ and III/IV stage of the disease $(\mathrm{OR}=2.75$; CI95\%=1.31-5.76). Finally, we found that women between $30-39$ years old were more likely to be infertile than those younger than 29 years $(\mathrm{OR}=2.72 ; \mathrm{CI} 95 \%=1.02-7.24)$. We also observed that women whose uterine tubes were 
Table 1

\begin{tabular}{|c|c|c|}
\hline Variables & $\mathrm{N}$ & $\%$ \\
\hline \multicolumn{3}{|l|}{ Age (year) } \\
\hline$\leq 29$ & 44 & 18.6 \\
\hline $30-39$ & 111 & 46.8 \\
\hline$\geq 40$ & 73 & 30.8 \\
\hline Missing & 9 & 3.8 \\
\hline \multicolumn{3}{|l|}{ Marital status } \\
\hline Single & 78 & 32.9 \\
\hline Married & 135 & 57.0 \\
\hline Divorced/separated & 13 & 5.5 \\
\hline Widowed & 1 & 0.4 \\
\hline Missing & 10 & 4.2 \\
\hline \multicolumn{3}{|l|}{ Educational level } \\
\hline Primary school & 33 & 13.9 \\
\hline High school & 114 & 48.1 \\
\hline Higher education & 82 & 34.6 \\
\hline Missing & 8 & 3.4 \\
\hline \multicolumn{3}{|l|}{ BMI $\left(\mathrm{kg} / \mathrm{m}^{2}\right)$} \\
\hline$<18.5$ & 12 & 5.1 \\
\hline $18.5-24.9$ & 81 & 34.2 \\
\hline $25-29.9$ & 78 & 32.9 \\
\hline $30-40$ & 60 & 25.3 \\
\hline$>40$ & 3 & 1.3 \\
\hline Missing & 3 & 1.3 \\
\hline \multicolumn{3}{|l|}{ Physical activity } \\
\hline No & 93 & 39.2 \\
\hline Yes* & 136 & 57.4 \\
\hline Missing & 8 & 3.4 \\
\hline \multicolumn{3}{|l|}{ Smoking status } \\
\hline Smoker & 22 & 9.3 \\
\hline Never smoked & 192 & 81.0 \\
\hline Ex-smoker & 22 & 9.3 \\
\hline Missing & 1 & 0.4 \\
\hline \multicolumn{3}{|l|}{ Alcohol consumption } \\
\hline No & 96 & 40.5 \\
\hline Yes & 100 & 42.2 \\
\hline Ex-alcoholic & 32 & 13.5 \\
\hline Missing & 9 & 3.8 \\
\hline \multicolumn{3}{|l|}{ Parity** } \\
\hline 0 & 60 & 32.3 \\
\hline 1 & 59 & 31.7 \\
\hline 2 & 34 & 18.3 \\
\hline$\geq 3$ & 19 & 10.2 \\
\hline Missing & 14 & 7.5 \\
\hline \multicolumn{3}{|l|}{ Spontaneous abortion** } \\
\hline No & 142 & 76.3 \\
\hline Yes & 37 & 19.9 \\
\hline Missing & 7 & 3.8 \\
\hline
\end{tabular}

continue

$\mathrm{BMI}=$ body mass index; IUD= intrauterine device; * Past and present physical activity; * Fifty-one patients were not included because they did not attempt to get pregnant; $* * * A$ patient can use more than one contraception type; $* * * *$ Family history only in first-degree relatives. 


\begin{tabular}{lcc}
\hline Sociodemographic characteristics of the studied population $(\mathrm{N}=237)$. & \\
\hline Variables & $\mathbf{N}$ & $\%$ \\
\hline Contraception use*** & 208 & 87.7 \\
Oral & 67 & 28.3 \\
Injectable & 19 & 8.0 \\
IUD & 1 & 0.4 \\
Missing & & \\
History of endometriosis**** & 178 & 75.1 \\
No & 47 & 19.8 \\
Yes & 12 & 5.1 \\
Missing & & \\
\hline
\end{tabular}

$\mathrm{BMI}=$ body mass index; IUD= intrauterine device; * Past and present physical activity; * Fifty-one patients were not included because they did not attempt to get pregnant; $* * *$ A patient can use more than one contraception type; $* * * *$ Family history only in first-degree relatives.

\section{Figure 1}

Frequency of the individual and concomitant symptoms in the studied population.

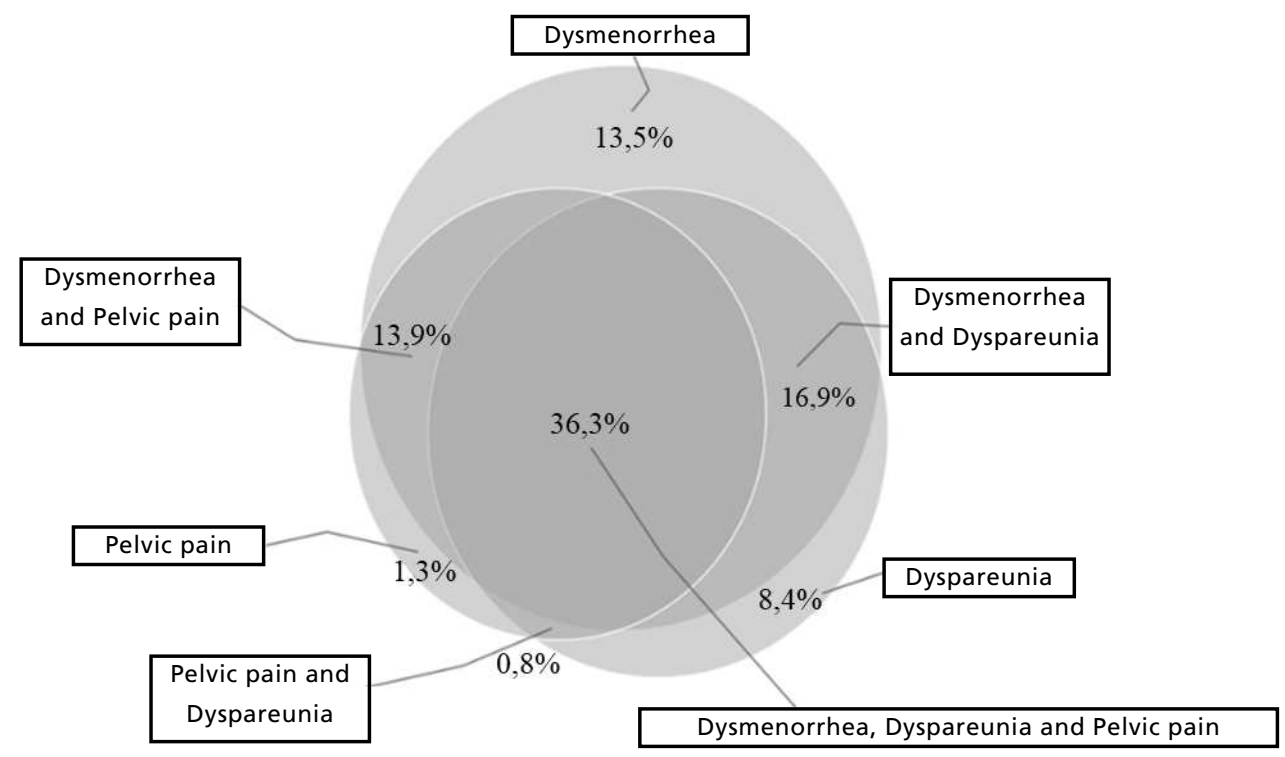

affected by endometriosis were more likely to have infertility $(\mathrm{OR}=2.91 ; \mathrm{CI} 95 \%=1.18-7.17)$.

Table 3 shows the demographic and clinical differences between cases diagnosed by surgery and image, DIE and non-DIE cases and between endometriosis stages I/II and III/IV. We found that patients diagnosed by surgery were significantly older (mean age $36.9 \pm 7.0$ years), were more likely to be married and had a lower parity than those diag- nosed by image. Women with DIE showed a higher educational level and were more likely to be never smokers than the ones without DIE. We observed that stage III/IV patients were more likely to be married, to practice some regular physical activity than the ones with endometriosis stage I/II.

The mean time between the first endometriosis symptoms and diagnosis was $4.5 \pm 6.5$ years for all cases. Significant differences were observed 
Table 2

\begin{tabular}{|c|c|c|}
\hline Variables & $\mathbf{N}$ & $\%$ \\
\hline \multicolumn{3}{|l|}{ Symptoms* } \\
\hline Dysmenorrhea & 191 & 80.6 \\
\hline Non-cyclic chronic pelvic pain & 124 & 52.3 \\
\hline Deep dyspareunia & 150 & 63.3 \\
\hline Cyclical intestinal complaints** & 111 & 46.8 \\
\hline Cyclical urinary complaints** & 54 & 22.8 \\
\hline Asymptomatic & 14 & 5.9 \\
\hline \multicolumn{3}{|l|}{ Infertility*** } \\
\hline No & 93 & 50.5 \\
\hline Yes & 91 & 49.5 \\
\hline \multicolumn{3}{|l|}{ Diagnostic method } \\
\hline MRI & 88 & 37.1 \\
\hline Laparoscopy & 110 & 46.4 \\
\hline Laparotomy & 34 & 14.4 \\
\hline Laparoscopy and laparotomy & 5 & 2.1 \\
\hline \multicolumn{3}{|l|}{ Endometriosis type } \\
\hline SUP & 31 & 13.1 \\
\hline OMA & 60 & 25.3 \\
\hline DIE & 145 & 61.2 \\
\hline Missing & 1 & 0.4 \\
\hline \multicolumn{3}{|l|}{ Endometriosis staging $* \star \star *$} \\
\hline $1 / I I$ & 58 & 38.9 \\
\hline III/IV & 83 & 55.7 \\
\hline Missing & 8 & 5.4 \\
\hline \multicolumn{3}{|c|}{ Organs affected by endometriosis $* \star \star \star *$} \\
\hline Ovary & 154 & 65.0 \\
\hline Uterosacral ligament & 72 & 30.4 \\
\hline Rectosigmoid & 59 & 24.9 \\
\hline Peritoneum & 50 & 21.1 \\
\hline Intestine & 45 & 19.0 \\
\hline Bladder & 40 & 16.9 \\
\hline Uterine tubes & 29 & 12.2 \\
\hline Rectovaginal septum & 25 & 10.5 \\
\hline Others & 23 & 9.7 \\
\hline \multicolumn{3}{|l|}{ Number of ectopic loci } \\
\hline 1 & 104 & 43.9 \\
\hline 2 to 4 & 114 & 48.1 \\
\hline$>4$ & 16 & 6.7 \\
\hline Missing & 3 & 1.3 \\
\hline
\end{tabular}

$\mathrm{MRI}=$ magnetic resonance imaging; SUP = superficial endometriosis; OMA = ovarian endometrioma; DIE = deeply infiltrating endometriosis; * A patient can have more than one concomitant symptom; ** Pain and bleeding; *** Primary or secondary. Fifty-three patients had no attempt to conceive and were excluded from this analysis; $* * * *$ Refers to patients diagnosed by surgery $(\mathrm{N}=149) ; * * * * * A$ patient can have more than one endometriotic foci. 
Comparison between asymptomatic and symptomatic women for dysmenorrhea, deep dyspareunia, cyclical intestinal complaints and infertility, regarding the demographic, clinical and menstrual characteristics of the studied population.

A. Dysmenorrhea
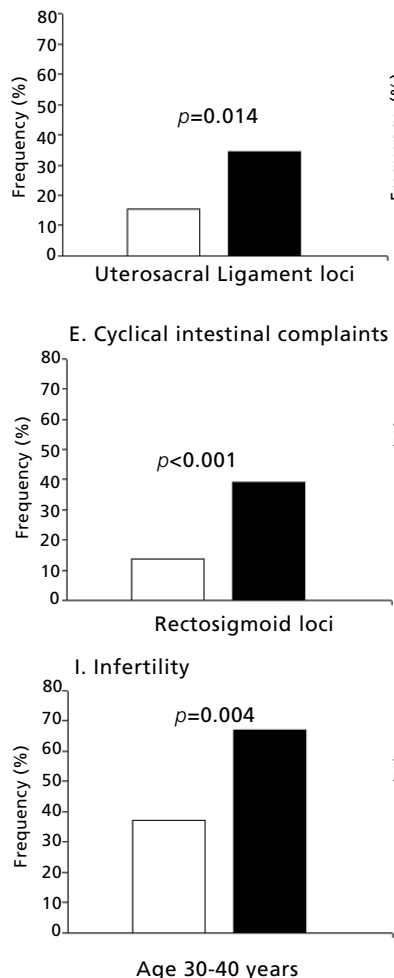

B. Dyspareunia

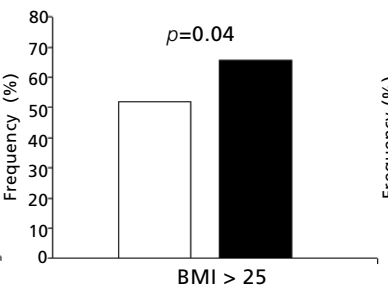

F. Cyclical intestinal complaints
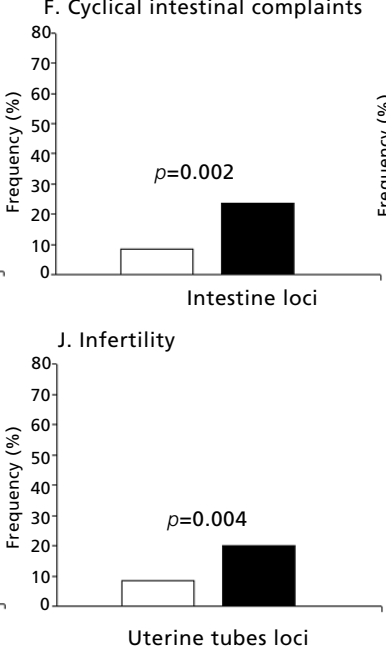

C. Dyspareunia

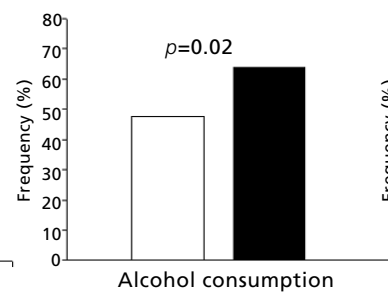

G. Cyclical intestinal complaints

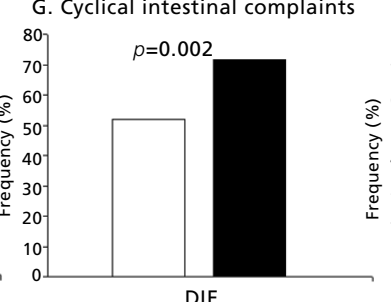

D. Dyspareunia

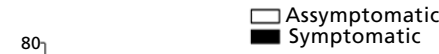

Symptomatic

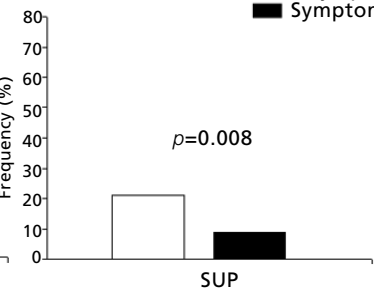

H. Cyclical intestinal complaints

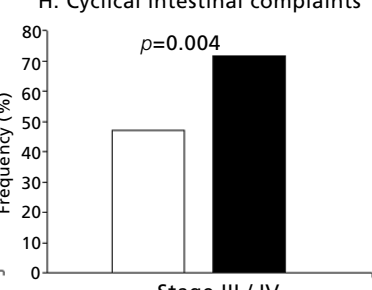

Stage III / IV

(A) dysmenorrhea; (B-D) deep dyspareunia; (E-H) cyclical intestinal complaints; (I-J) infertility. p-value from Chi-square test (Pearson $p$ value); SUP = superficial endometriosis; DIE = deeply infiltrating endometriosis; BMI= body mass index.

between endometriosis stages I/II and III/IV (3.3 \pm 4.1 and $5.3 \pm 7.5$ years) and between DIE versus non-DIE patients $(3.8 \pm 5.4$ and $5.2 \pm 7.0$ years $)$, showing that advanced stages and DIE had a longer diagnosis time than initial stage and non-DIE. However, no statistical differences were found between patients with diagnosis confirmed by surgery or by image methods.

\section{Discussion}

Endometriosis is usually present in women of reproductive age, 2,3 according to the mean age (36 years) described in the present study. The endometriosis risk associated to a lower BMI has been described but remains an enigma.2,3,9 Our findings agree with earlier large cross-sectional and case-control studies linking an inverse association between endometriosis and BMI.2,3,9 A cross-sectional study, in 2017, involving surgical cohort (273 women) found endometriosis was inversely associated with anthropometric measures and body composition indicators. ${ }^{9}$ However, the biosynthesis of estrogen, an important hormone that contributes to endometriosis progression, occurs primarily in the ovaries, but also occurs in the adipose tissue and subcutaneous fat in the body. 18 Thus, biologically, the low BMI cannot be explained in women with endometriosis. Therefore, the relationship between endometriosis and BMI, and the genetic and mole- 


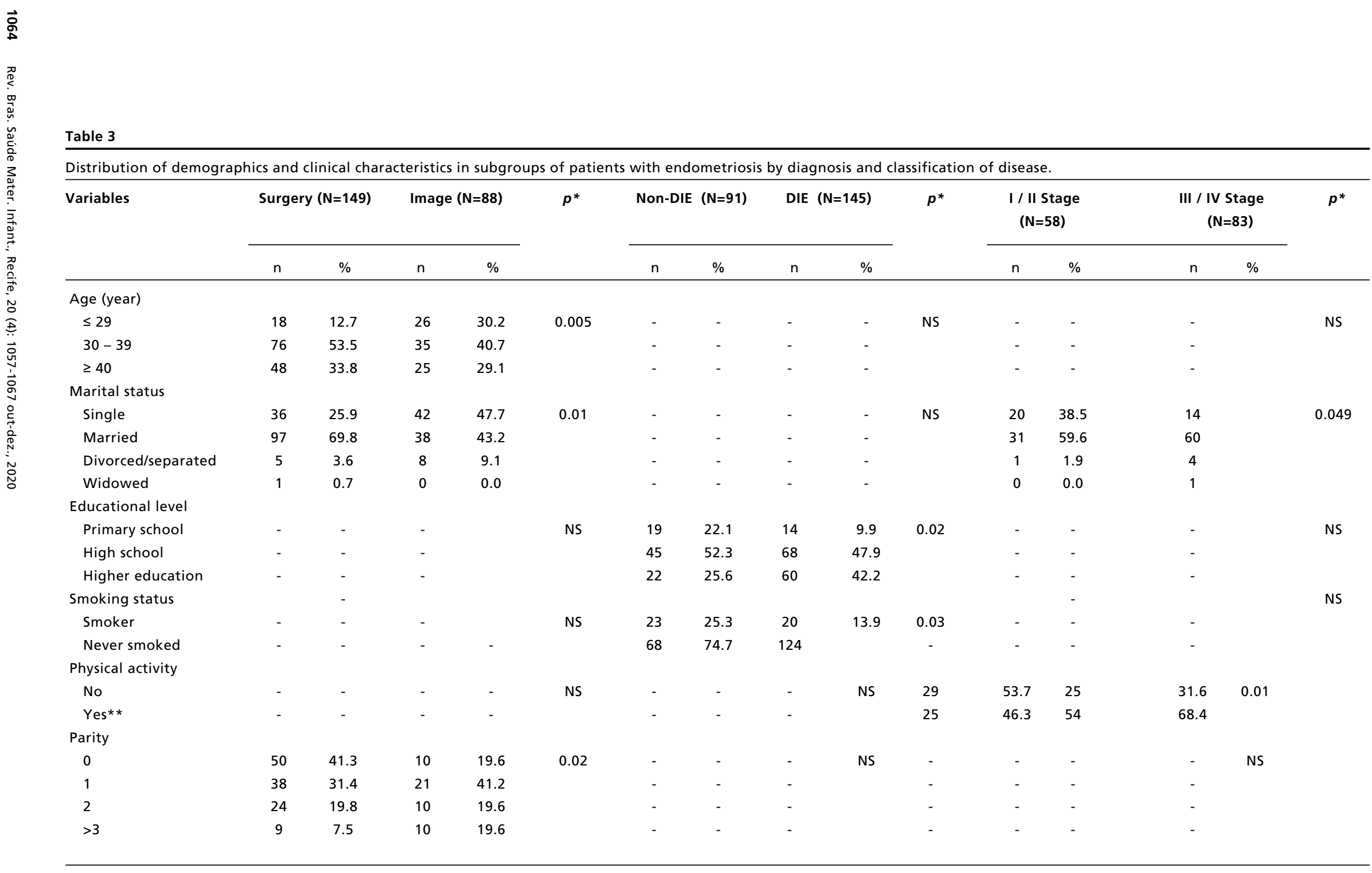

DIE = deeply infiltrating endometriosis; NS and $(-)=$ Non-significant results; * Chi-square test or Fisher's exact test; ** Past and present physical activity. 
cular effects upon body weight still needs to be elucidated. Regarding the hereditary influence in endometriosis features, positive associations about family history of endometriosis have been suggested in several studies. 1,19

Patients with endometriosis reported to be married and had higher educational level, corroborating with previous qualitative and case-control studies. ${ }^{3,15,20}$ Chapron et al. ${ }^{3}$ conducted a multicountry case-control study, in 2016, comprising 1008 women with endometriosis and showed a higher frequency of married and university-educated women among endometriosis cases in comparison with disease free women. Nowadays, women use contraceptives more often and for a longer period, therefore only discover the presence of the disease when they decide to get pregnant. 21 We also observed that most women used contraceptives, and had menarche around 12 years old, in agreement with recent studies. 3,13,22

Regarding lifestyle features, we found that patients had the habit of practicing physical activity and alcohol consumption, also most of them never smoked. Some studies have reported that women with endometriosis consume more alcohol,11,23 perform more physical activities 22 and usually don't smoke in accordance with our findings. 3,9 However, other articles have found different results, 11,24 showing that there are some controversies and, therefore, further studies are needed to better understand the relation between these variables and endometriosis.

More than one third of the patients had all three symptoms of gynecological pain combined, according to a cross-sectional study, published in 2008 , with a cohort of 1000 women from Britain, Ireland, and the United States, whose frequency of dysmenorrhea, dyspareunia and chronic pelvic pain combined was $34.4 \%{ }^{14}$ Regarding all disease symptoms (dysmenorrhea, dyspareunia, chronic pelvic pain, intestinal and urinary complaints), a few patients in this study were asymptomatic, which does not corroborate with a qualitative descriptive study, with 35 participants, published by Moradi et al. 20

However, this finding can be explained by the fact that our two recruiting hospitals are specialized centers for the diagnosis and treatment of endometriosis and, thus, most women sought medical attention there due to the occurrence of any symptom. In addition, the recruitment time between the first symptoms of endometriosis and the diagnosis was similar ( $\sim 5$ years) to that found in other recent studies. 25,26

Women with SUP had decreased risk of dyspareunia, according to Chapron et al., ${ }^{3}$ since the peritoneum area is less likely to be struck during intercourse. Endometriosis may cause dyspareunia by tension on the infiltrated uterosacral ligament during intercourse, since the distance between ectopic endometrial growths and nerve fibers in women with this symptom is shortened. ${ }^{27}$ We have also observed that intestinal symptoms are positively associated with DIE in the rectosigmoid and intestine loci, and with DIE classification and the advanced stages of the disease. It is to be considered the pain to evacuate may be due to infiltrative lesions. ${ }^{28}$ Finally, infertile women had almost a 3 -fold increase in the risk of endometriotic lesions in uterine tubes. Previous reports have described that uterine tube's diseases accounts for $25-35 \%$ of all female primary infertility cases and can be associated with endometriosis.28-30 In addition, women between 3039 years were associated with increased risk of infertility. Briceag et al. ${ }^{29}$ performed a review through an international database and showed that the risk of having a diagnosis of tubal factor infertility at 35-39 years was 2 times higher than those under 30 years. In addition, in present study, women at this age group may have searched the doctor due to infertility, leading to a selection bias.

As expected, most patients were diagnosed by laparoscopy, in agreement with recent multi-country case-control studies with large hospital and population samples, 3,24 since it is the gold standard for endometriosis diagnosis. ${ }^{1}$ Currently, laparoscopy treatment is recommended preferably in cases of infertility, untreatable pain and/or those with significant involvement of the intestine or urinary tract with risk of functional impairment. ${ }^{17}$ In our study, $37 \%$ of women were diagnosed by MRI, which have been described as an accurate method for the detection of deep endometriosis due to its high specificity and sensibility. ${ }^{16}$ Nevertheless, SUP cases, mainly, can be underdiagnosed. 16 The present study showed that most sociodemographic and clinical variables had similar frequencies between women who underwent surgery versus imaging diagnosis; however, those diagnosed by image were younger, had greater parity and were most likely to be single. We hypothesized that older women perform surgical diagnosis to treat possible infertility, which also explains the fact that they are, for the most part, married and therefore trying to conceive a child.

A larger sample size would be required to detect more associations and provide more confidence in 
the findings. Additionally, as this is an observational study, it is possible that there are still unmeasured variables, which forbids the complete exclusion of residual confounding. However, this bias has minimal effect given the adjustment by various confounding factors. A referral bias has also to be raised: patients included in this study are treated in two reference institutions for endometriosis. These patients may have more severe symptomatology as they were probably referred to these centers, biasing the results. It is not possible to assure that these associations are causal, however, this epidemiological analysis is an important tool in the identification of endometriosis' etiology. Furthermore, by understanding endometriosis' epidemiological profile, it would be possible to determine a guideline to improve diagnosis, prognosis and treatment of the disease.

In summary, dysmenorrhea, dyspareunia, cyclical intestinal complaints, surgical diagnosis, DIE and advanced stage endometriosis were associated with either sociodemographic or clinical variables of endometriosis.

\section{Acknowledgments}

The authors thank all the staff of the two recruitment hospitals (HFSE and HMF) for their technical assistance and who have contributed to realization this study.

\section{References}

1. Zondervan KT, Becker CM, Missmer SA. Endometriosis. N Engl J Med. 2020; 382 (13): 1244-56.

2. Eisenberg VH, Weil C, Chodick G, Shalev V. Epidemiology of endometriosis: a large population-based database study from a healthcare provider with 2 million members. An Int J Gynaecol Obstet. 2018; 125 (1): 55-62.

3. Chapron C, Lang JH, Leng JH, Zhou Y, Zhang X, Xue M, Popov A, Romanov V, Maisonobe P, Cabri P. Factors and regional differences associated with endometriosis: a multicountry, case-control study. Adv Ther. 2016;33(8):1385407

4. Cardoso JV, Abrão MS, Vianna-Jorge R, Ferrari R, Berardo PT, Machado DE, Perini JA. Combined effect of vascular endothelial growth factor and itsreceptor polymorphisms in endometriosis: a case-control study. Eur J Obstet Gynecol Reprod Biol. 2017; 209: 25-33.

5. Hughes CL, Foster WG, Agarwal SK, Mettler L. The Impact of Endometriosis on the Health of Women. Biomed Res Int. $2015 ; 365951$.

6. Koltermann KC, Schlotmann A, Schröder H, Willich SN, Reinhold T. Economic burden of deep infiltrating endometriosis of the bowel and the bladder in Germany:

\section{Author's contribution}

Cardoso JV carried out the research, recruited the patients from the Hospital Moncorvo Filho and Hospital dos Servidores do Estado, analyzed data and wrote the manuscript. Machado DE contributed to critical discussion of manuscript. Silva MC recruited the patients from the Hospital dos Servidores do Estado, contributed to data collection and contributed to writing the manuscript. Berardo PT followed the patients from the Hospital dos Servidores do Estado, contributed to data collection and to critical discussion and to edit the manuscript. Ferrari R recruited and followed the patients from the Hospital Moncorvo Filho. Abrão MS contributed to critical discussion of manuscript. Perini JA conceived and designed the research, supervised the data collection, analyzed data, wrote the manuscript and obtained funding. All authors approved the final version of the article.
The statutory health insurance perspective. Z Evid Fortbild Qual Gesundhwes. 2016; 118-119: 24-30.

7. Ferrero S, Remorgida V, Maganza C, Venturini PL, Salvatore S, Papaleo E, Candiani M, Maggiore ULR. Aromatase and endometriosis: estrogens play a role. Ann N Y Acad Sci. 2014; 1317: 17-23.

8. Riccio LDGC, Santulli P, Marcellin L, Abrão MS, Batteux F, Chapron C. Immunology of endometriosis. Best Pract Res Clin Obstet Gynaecol. 2018; 50: 39-49.

9. Backonja U, Hediger ML, Chen Z, Lauver DR, Sun L, Peterson CM, Louis GMB. Beyond Body Mass Index: Using Anthropometric Measures and Body Composition Indicators to Assess Odds of an Endometriosis Diagnosis. J Womens Health (Larchmt). 2017; 26 (9): 941-50.

10. Calhaz-Jorge C, Mol BW, Nunes J, Costa AP. Clinical predictive factors for endometriosis in a Portuguese infertile population. Hum Reprod. 2004; 19 (9): 2126-31.

11. Heilier JF, Donnez J, Nackers F, Rousseau R, Verougstraete V, Rosenkranz K, Donnez O, Grandjean F, Lison D, Tonglet R. Environmental and host-associated risk factors in endometriosis and deep endometriotic nodules: a matched case-control study. Environ Res. 2007; 103 (1): 121-9. 
12. Prescott J, Farland LV, Tobias DK, Gaskins AJ, Spiegelman D, J.E. Chavarro, Rich-Edwards JW, Barbieri RL, Missmer SA. A prospective cohort study of endometriosis and subsequent risk of infertility. Hum Reprod. 2016; 31 (7): 147582.

13. Peterson CM, Johnstone EB, Hammoud AO, Stanford JB Varner MW, Kennedy A, et al. Risk factors associated with endometriosis: importance of study population for characterizing disease in the ENDO Study. Am J Obstet Gynecol. 2013; 208 (6): 451.e1-11.

14. Sinaii N, Plumb K, Cotton L, Lambert A, Kennedy S, Zondervan K, Stratton, P. Differences in characteristics among 1,000 women with endometriosis based on extent of disease. Fertil Steril. 2008; 89 (3): 538-45.

15. Liu X, Long Q, Guo SW. Surgical History and the Risk of Endometriosis: A Hospital-Based Case-Control Study. Reprod Sci. 2016; 23 (9): 1217-24.

16. Barcellos MB, Lasmar B, and Lasmar R. Agreement between the preoperative findings and the operative diagnosis in patients with deep endometriosis. Arch Gynecol Obstet. 2016; 293 (4): 845-50.

17. Kho RM, Andres MP, Borrelli GM, Neto JS, Zanluchi A, and Abrão MS. Surgical treatment of different types of endometriosis: Comparison of major society guidelines and preferred clinical algorithms. Best Pract Res Clin Obstet Gynaecol. 2018; 51: 102-10.

18. Bulun SE, Chen D, Moy I, Brooks DC and Zhao $\mathrm{H}$. Aromatase, breast cancer and obesity: a complex interaction. Trends Endocrinol Metab. 2012; 23 (2): 83-9.

19. Audebert A, Lecointre L, Afors K, Koch A, Wattiez A, Akladios C. Adolescent Endometriosis: Report of a Series of 55 Cases With a Focus on Clinical Presentation and Long-Term Issues. J Minim Invasive Gynecol. 2015; 22 (5): 834-40.

20. Moradi M, Parker M, Sneddon A, Lopez V, Ellwood D. Impact of endometriosis on women's lives: a qualitative study. BMC Women's Health. 2014; 14: 123.

21. Hemmings R, Rivard M, Olive DL, Poliquin-Fleury J, Gagné D, Hugo P,Gosselin D. Evaluation of risk factors associated with endometriosis. FertilSteril. 2004; 81 (6) 1513-21.

Received on June 2, 2019

Final version presented on August 20, 2020

Approved on September 2, 2020
22. Farland LV, Missmer SA, Bijon A, Gusto G, Gelot A, Clavel-Chapelon F, Mesrine S Boutron-Ruault MC, Kvaskoff M. Associations among body size across the life course, adult height and endometriosis. Hum Reprod. 2017; 32 (8): 1732-42.

23. Parazzini F, Cipriani S, Bravi F, Pelucchi C, Chiaffarino F, Ricci E, Viganò P. A metaanalysis on alcohol consumption and risk of endometriosis. Am J Obstet Gynecol. 2013. 209 (2): 106.e1-10.

24. Hemmert R, Schliep KC, Willis S, Peterson CM, Louis GB, Allen-Brady K, Simonsen SE, Stanford JB, Byun J, Smith KR. Modifiable life style factors and risk for incident endometriosis. Paediatr Perinat Epidemiol. 2019; 33 (1): 19-25.

25. Soliman AM, Fuldeore M, and Snabes MC. Factors associated with time to endometriosis diagnosis in the United States. J Women's Health. 2017; 26 (7): 788-97.

26. van der Zanden M, Arens MWJ, Braat DDM, Nelen WLM, Nap AW. Gynaecologists' view on diagnostic delay and care performance in endometriosis in the Netherlands. Reprod Biomed Online. 2018; 37 (6): 761-8.

27. Tulandi T, Felemban A,Chen MF. Nerve fibers and histopathology of endometriosis-harboring peritoneum. J Am Assoc Gynecol Laparosc. 2001; 8 (1): 95-8.

28. Pandian Z, Akande VA, Harrild K, Bhattacharya S. Surgery for tubal infertility. Cochrane Database Syst Rev. 2008; (3): CD006415

29. Briceag I, Costache A, Purcarea VL, Cergan R, Dumitru M, Briceag I, Sajin M, Ispas AT. Fallopian tubes--literature review of anatomy and etiology in female infertility. J Med Life. $2015 ; 8$ (2): 129-31.

30. Pereira N, Kligman I. Clinical implications of accessory fallopian tube ostium in endometriosis and primary infertility. Womens Health (Lond). 2016; 12 (4): 404-6. 